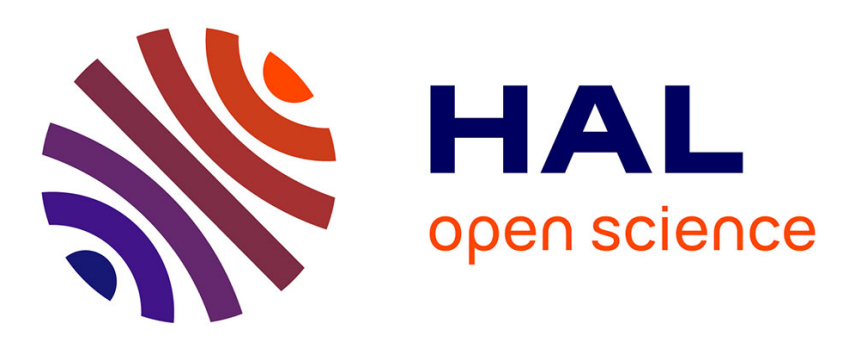

\title{
ON/OFF Photoswitching and Thermoinduced Spin Crossover with Cooperative Luminescence in a 2D Iron(II) Coordination Polymer
}

Subrata Ghosh, Sujit Kamilya, Titas Pramanik, Mathieu Rouzières, Radovan Herchel, Sakshi Mehta, Abhishake Mondal

\section{To cite this version:}

Subrata Ghosh, Sujit Kamilya, Titas Pramanik, Mathieu Rouzières, Radovan Herchel, et al.. ON/OFF Photoswitching and Thermoinduced Spin Crossover with Cooperative Luminescence in a 2D Iron(II) Coordination Polymer. Inorganic Chemistry, 2020, 59, pp.13009 - 13013. 10.1021/acs.inorgchem.0c02136 . hal-03086345

\section{HAL Id: hal-03086345 https://hal.science/hal-03086345}

Submitted on 22 Dec 2020

HAL is a multi-disciplinary open access archive for the deposit and dissemination of scientific research documents, whether they are published or not. The documents may come from teaching and research institutions in France or abroad, or from public or private research centers.
L'archive ouverte pluridisciplinaire HAL, est destinée au dépôt et à la diffusion de documents scientifiques de niveau recherche, publiés ou non, émanant des établissements d'enseignement et de recherche français ou étrangers, des laboratoires publics ou privés. 


\title{
ON/OFF Photoswitching and Thermoinduced Spin Crossover with Cooperative Luminescence in a 2D Iron(II) Coordination Polymer
}

\author{
Subrata Ghosh, Sujit Kamilya, Titas Pramanik, Mathieu Rouzières, Radovan Herchel, Sakshi Mehta, \\ and Abhishake Mondal*
}

ABSTRACT: A 2D coordination polymer, $\left\{\left[\mathrm{Fe}(\mathrm{L})_{2}(\mathrm{NCSe})_{2}\right] \cdot 6 \mathrm{MeOH} \cdot 14 \mathrm{H}_{2} \mathrm{O}\right\}_{n}(\mathbf{1} ; \mathbf{L}=2,5$-dipyridylethynylene-3,4-ethylenedioxythiophene), has been synthesized based on a redox active luminescence ligand. 1 possesses a $2 \mathrm{D}$ [ $4 \times 4]$ square-grid network where the iron(II) center is in a $\mathrm{FeN}_{6}$ octahedral coordination environment. 1 displays reversible thermoinduced high-spin (HS; $S=2$ ) to diamagnetic low-spin (LS; $S=0$ ) ON/OFF spin-state switching with a $T_{1 / 2}$ value of $150 \mathrm{~K}$. Interestingly, optical reflectivity and photomagnetic studies at $10 \mathrm{~K}$ under light irradiation revealed an efficient conversion to a photoinduced metastable HS excited state from a LS ground state. Remarkably, the photoexcited HS state can be reversibly switched ON and OFF by using 625 and $850 \mathrm{~nm}$ light-emitting-diode lights. Intriguingly, the thermal dependence of the luminescence intensity of the maximum emission at $524 \mathrm{~nm}$ for 1 shows a minimum at around the spin-crossover (SCO) temperature, indicating a cooperative nature between the SCO and luminescence properties. Theoretical calculations confirmed the above findings.

S pin manipulation in molecules triggered by minute alteration of the external stimulus is an attractive and fascinating topic in quantum science and technology. ${ }^{1,2}$ Spincrossover (SCO) materials represent a significant way for understanding the molecular spintronics, sensors, switches, nanoscale data recording, and storage devices according to their intrinsic bistable property. ${ }^{3-7}$ The rational design of a stimuli-responsive multifunctional coordination polymer (CP) by the incorporation of one or more additional cooperative properties, e.g., magnetic, electric, and optical, with the intrinsic properties, e.g., permanent and tunable porosity, versatile structural topologies, and physicochemical properties, has recently gained significant attention. ${ }^{8-17}$ In this aspect, the simultaneous incorporation of both SCO and luminescence properties in a CP is challenging but highly attractive because modulation of the luminescence signal can signify low-spin (LS)/high-spin (HS) population during spin-state switching. ${ }^{18-25}$ As a successful synthetic strategy to improve cooperativity between SCO and luminescence properties, the direct coupling between the SCO unit and appropriate luminescent organic linkers to form extended structures is significantly important, and it is challenging to interplay such cooperative properties, which have been rarely investigated in 2D multifunctional CPs.

In this aspect, herein we present one $2 \mathrm{D} \mathrm{CP}$ by introducing $\mathrm{Fe}(\mathrm{NCSe})_{2}$ with a novel 3,4-ethylenedioxythiophene-based ditopic nitrogen-donor ligand L (Scheme S1), which exhibits cooperative SCO and luminescence properties along with exciting ON/OFF photoswitching behavior.

The reaction of a methanolic solution of Fe:2NCSe with ligand $\mathbf{L}$ in dichloromethane (DCM) afforded $\mathbf{1}$ as red crystals (see Figures S1-S9 for detailed characterization). Variabletemperature X-ray diffraction analyses were performed on a single crystal of 1 at 120 and $200 \mathrm{~K}$, respectively (Tables S1 and S2). 1 crystallizes in the orthorhombic space group Ccca. Its structure consists of the neutral molecular motif [Fe$\left.(\mathrm{L})_{2}(\mathrm{NCSe})_{2}\right]_{n}$ and interstitial methanol $(\mathrm{MeOH})$ and water solvent molecules (Figures 1 and S10). The overall coordination geometry around each iron center is best described by a slightly distorted octahedron with a $\mathrm{FeN}_{6}$ environment (CShM program; ${ }^{26}$ Table S3), where the iron center is coordinated to the four nitrogen-donor atoms of four monodentate $\mathbf{L}$ ligands and two nitrogen-donor atoms of two $\mathrm{NCSe}^{-}$coligands. Ligand $\mathrm{L}$ is also acting as a bridging ligand to connect iron centers to form the extended $2 \mathrm{D}[4 \times 4]$ square-grid networks (Figure 1).

At $200 \mathrm{~K}$, the average $\mathrm{Fe}-\mathrm{N}_{\mathrm{Py}}$ and $\mathrm{Fe}-\mathrm{N}_{\mathrm{NCSe}}$ bond distances are 2.212 and $2.090 \AA$ respectively, which suggested the HS state of the iron center (Figure S11 and Table S2).$^{27-29}$ Upon lowering the temperature to $120 \mathrm{~K}$, the overall structural motif remains unchanged; however, a great difference occurs in the iron(II) coordination sphere. The average $\mathrm{Fe}-\mathrm{N}_{\mathrm{Py}}$ and $\mathrm{Fe}-\mathrm{N}_{\mathrm{NCSe}}$ bond distances reduce to 1.999 and $1.941 \AA$, respectively (Figure S11 and Table S2), which fall in the range expected for the LS iron(II) ion. ${ }^{27-29}$ The coordinated $\mathrm{NCSe}^{-}$coligands are almost linear $[\angle \mathrm{N}-\mathrm{C}-\mathrm{Se}$ $\left.=178.6(7)^{\circ}\right]$; however, $\angle \mathrm{Fe}-\mathrm{N}-\mathrm{C}$ angles are deviated from linearity $\left[168.4(5)^{\circ}\right]$ at $200 \mathrm{~K}$ (Table S2). These values remain almost identical upon lowering of the temperature to $120 \mathrm{~K}$ (Table S2). The octahedral distortion parameter $\Sigma$ value of 


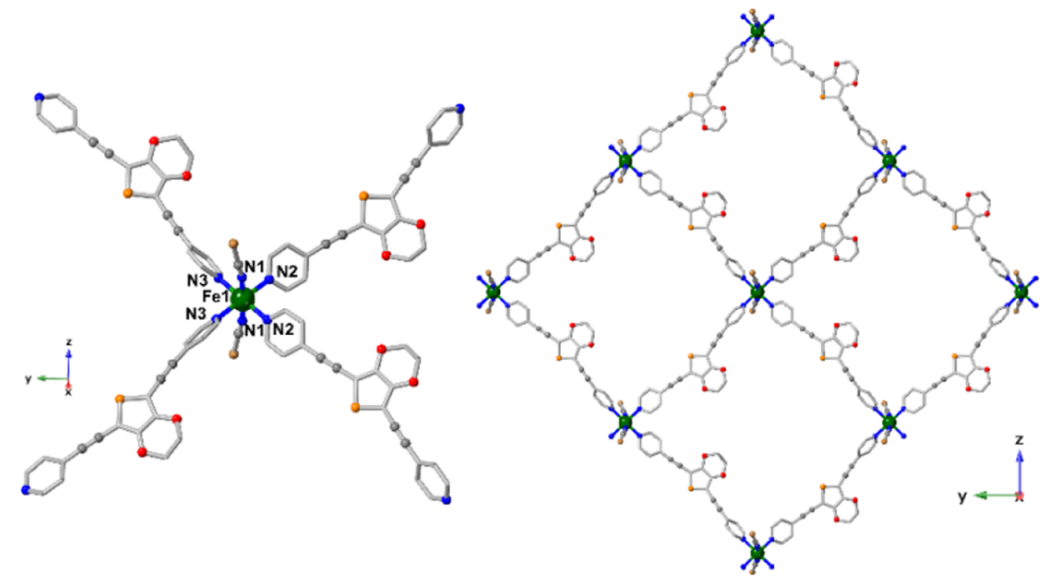

Figure 1. Coordination environment around the iron(II) (left) and 2D network showing a [4×4] square grid (right) in 1. Hydrogen atoms and solvent molecules are omitted for clarity (Fe, green; C, gray; N, blue; O, red; S, orange; Se, brown).

12.8 at $200 \mathrm{~K}$ compared to the value of 9.9 at $120 \mathrm{~K}$ also suggests the HS state of the iron(II) center at a higher temperature (Table S2), ${ }^{27-29}$ supported by CShM analyses (Table S3).

It is worth noting that a contraction in the $\mathrm{Fe}-\mathrm{N}_{\mathrm{py}}$ bond distance of around $0.2 \AA$ is observed, which indicates a complete spin-state switching from the HS to LS state of the iron centers. ${ }^{27-29}$ There is a concomitant decrease in the unit cell volume of around $4.5 \%$, the grid diagonal dimension from $\{28.55 \times 28.22\} \AA^{2}$ to $\{28.00 \times 27.72\} \AA^{2}$ and the $\mathrm{Fe} \cdots \mathrm{Fe}$ length through the bridging $L$ ligand from 20.07 to $19.70 \AA$ (Figure S12 and Table S2). Around a $6.7 \%$ decrease in the solvent-accessible void volume from 4126.6 to $3851.2 \AA^{3}$ with a drop from $37.3 \%$ to $36.4 \%$ of the crystal volume has also been observed.

Magnetic susceptibility measurements were carried out on both fresh crystals kept in a mother liquor ( $\mathrm{MeOH} / \mathrm{DCM}$ / diethyl ether) and a polycrystalline sample of 1 at a magnetic field of $1000 \mathrm{Oe}$ in the temperature range of $2-280 \mathrm{~K}$ (Figure 2). The measured $\chi T[\chi$ is magnetic susceptibility equal to $M$ /

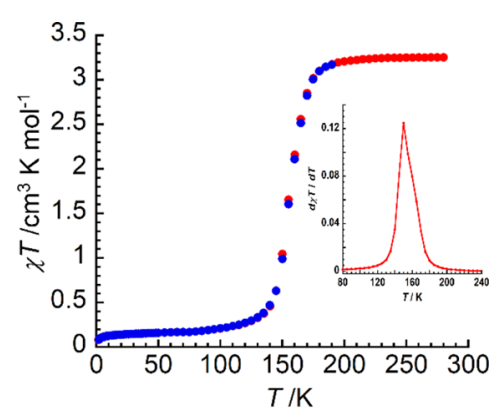

Figure 2. Temperature dependence of the $\chi T$ product for 1 at 1000 Oe in the cooling (blue) and heating (red) modes. Inset: $\mathrm{d} \chi \mathrm{T} / \mathrm{d} T$ versus $T$ identifies $T_{1 / 2}=150 \mathrm{~K}$ for $\mathbf{1}$.

$H$ per iron(II) ion] value at $280 \mathrm{~K}$ is $3.25 \mathrm{~cm}^{3} \mathrm{~mol}^{-1} \mathrm{~K}$, which lies in the expected range for the iron(II) ion in the HS state ( $S$ $\left.=2 ; g=2.0 ; \chi T=3.0 \mathrm{~cm}^{3} \mathrm{~mol}^{-1} \mathrm{~K}\right){ }^{27-29}$ Upon lowering of the temperature, the $\chi T$ value remains almost constant to 204 $\mathrm{K}$ and then decreases gradually to reach a value of $0.15 \mathrm{~cm}^{3}$ $\mathrm{mol}^{-1} \mathrm{~K}$ at $55 \mathrm{~K}$. The $\chi T$ value remains almost constant up to $10 \mathrm{~K}$, which indicates a complete and gradual HS-to-LS SCO in $1 .^{27-29} \mathrm{In}$ addition, the $\chi T$ value at $10 \mathrm{~K}$ corresponds to less than $2.5 \%$ of the residual HS iron(II) center. The small decrease of the $\chi T$ value below $10 \mathrm{~K}$ is probably due to the zero-field splitting of the residual HS iron(II) ion. The field dependence of magnetization studies for 1 were carried out from 0 to $7 \mathrm{~T}$ at $1.85,3,5$, and $8 \mathrm{~K}$ (Figure S14). At $1.85 \mathrm{~K}$ and $7 \mathrm{~T}$, the magnetization value is $0.11 \mu_{\mathrm{B}}$, which is due to the residual HS iron(II) center, matching well with the $\chi T$ data. In addition, $M$ versus $H / T$ measurement displays nonsuperposition of the magnetic data on a single master curve, probably is due to the presence of magnetic anisotropy coming from the residual HS iron(II) ion. It is worth mentioning that no out-ofphase $\left(\chi^{\prime \prime}\right)$ signal under a zero direct-current field of the alternating-current susceptibility was observed in $\mathbf{1}$, confirming the absence of a slow magnetic relaxation phenomenon (Figure S15).

The peak maxima of the $\mathrm{d}(\chi T) / \mathrm{d} T$ versus $T$ plot in the temperature range of $240-80 \mathrm{~K}$ indicate the SCO temperature $T_{1 / 2}$ at around $150 \mathrm{~K}$ in 1 . The identical magnetic responses in both the heating and cooling modes suggest a reversible ON/ OFF SCO for 1 . The best fit of the $\chi T$ versus $T$ data (Figure S16) using the ideal solution model ${ }^{30}$ gives the thermodynamic parameters $\Delta H=27.9(2) \mathrm{kJ} \mathrm{mol}^{-1}, T_{1 / 2}=155(1) \mathrm{K}$, and $\Delta S=$ $\Delta H / T_{1 / 2}=180 \mathrm{~J} \mathrm{~K}^{-1} \mathrm{~mol}^{-1}$, which lie in the range expected for the iron(II) SCO systems. ${ }^{27-29}$

Furthermore, optical-reflectivity studies have also been investigated between 270 and $10 \mathrm{~K}$ for 1 (Figure S17). Thermal evolution of the absolute reflectivity clearly indicates SCO between the HS and LS states around $150 \mathrm{~K}$, which is very close to the $T_{1 / 2}$ value.

To explore the photosensitivity of $\mathbf{1}$, the sample was irradiated with white light (WL; power $=0.5 \mathrm{~mW} \mathrm{~cm}^{-2}$ ) for ca. $100 \mathrm{~min}$ at $10 \mathrm{~K}$. The resultant spectrum significantly differs from the spectra obtained in the dark at both 10 and $270 \mathrm{~K}$ (Figure S18, left), suggesting the possibility of formation of the HS iron(II) state from the LS state of 1 at $10 \mathrm{~K}$. The evolution of absolute reflectivity versus time exhibits an increase in the absolute-reflectivity value, attaining a saturation after $20 \mathrm{~min}$ of WL irradiation (Figure S18, right). This value is matching well with the one obtained at $270 \mathrm{~K}$, which indicates a complete recovery of the $\mathrm{HS}$ state and thus suggests a complete photoinduced SCO of 1 from the LS state at $10 \mathrm{~K}$. After irradiation, the thermal stability of the photoinduced metastable HS state was also investigated by heating the sample in the dark (sweep rate $=0.4 \mathrm{~K} \mathrm{~min}^{-1}$; Figure 3, left), 

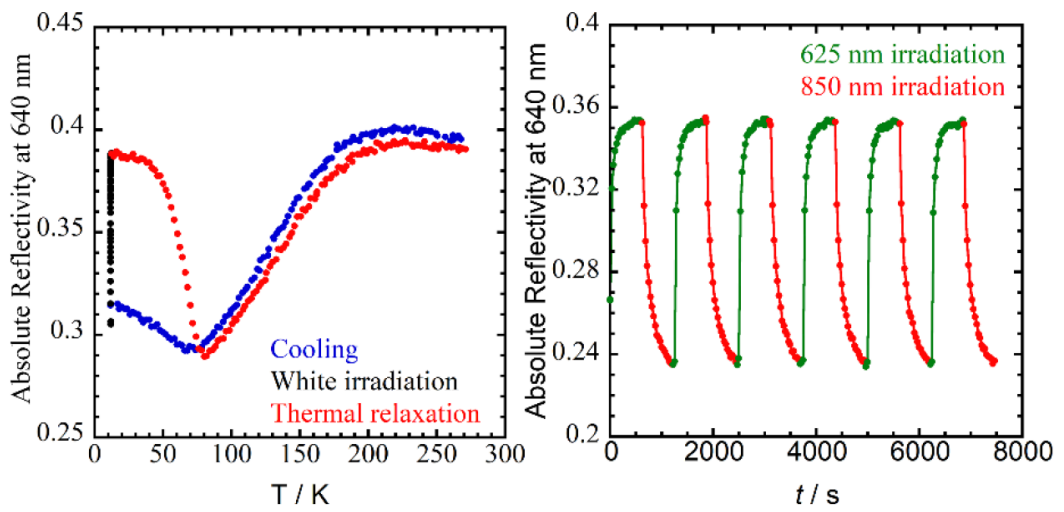

Figure 3. Left: Thermal evolution of the absolute-reflectivity signal plotted at $640 \mathrm{~nm}$ in the cooling mode, during WL irradiation (10 K), and in the heating mode for $\mathbf{1}$. Right: Time evolution of the absolute reflectivity under successive irradiations by 625 and $850 \mathrm{~nm}$ LEDs for 1 at $10 \mathrm{~K}$.
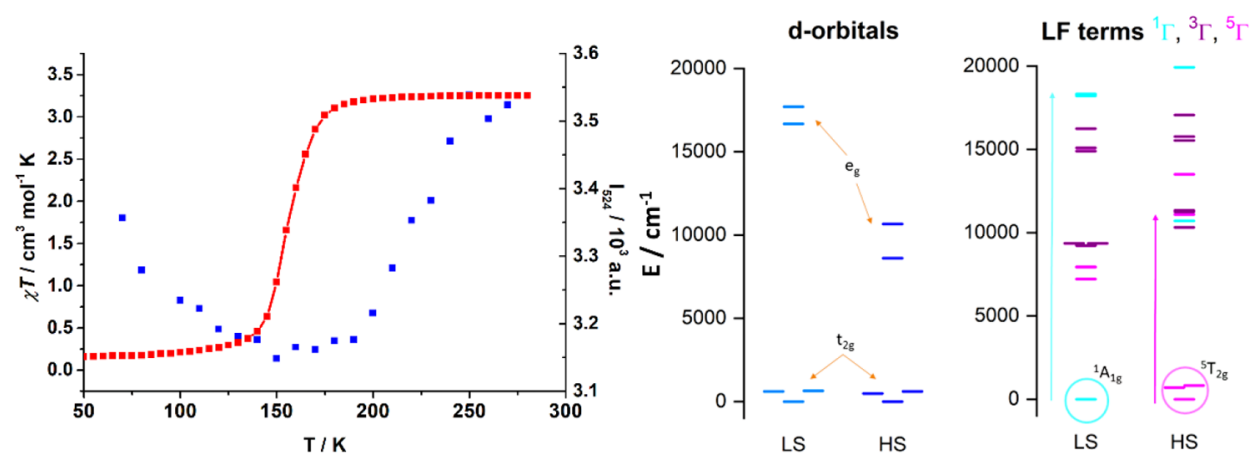

Figure 4. Left: Thermal variation of the luminescence intensity of the maximum emission $\left(\lambda_{\mathrm{em}}=524 \mathrm{~nm}\right)$ for 1 with a temperature dependence of the $\chi T$ product. Middle: Splitting of the d orbitals resulting from AILFT analysis of CASSCF/NEVPT2 for 1. Right: Ligand-field terms resulting from CASSCF/NEVPT2 calculations showing also possible excitation energies to the lowest state with the same multiplicity as the ground state.

which shows a decrease in the absolute reflectivity due to relaxation of the photoinduced HS state to the diamagnetic LS ground state, where a complete relaxation was observed at around $80 \mathrm{~K}\left(T_{\mathrm{LIESST}}\right)$. After this temperature, the absolutereflectivity values show a feature similar to that observed in the dark. Additional photoexcitation at $10 \mathrm{~K}$ with 14 light-emitting diodes (LEDs; 1050-365 nm) showed that all LEDs were able to populate the paramagnetic HS state (Figure S19), in agreement with the efficiency of $\mathrm{WL},{ }^{31-33}$ where a maximum efficiency was observed for $625 \mathrm{~nm}$. Accordingly, further photoexcitation studies were carried out with $625 \mathrm{~nm}$ LED irradiation at $10 \mathrm{~K}$, which led to similar outcomes (Figures S20 and S21). Interestingly, a weak time relaxation of the photoinduced metastable state in the dark at $10 \mathrm{~K}$ can be seen mainly in the first $5 \mathrm{~min}$ (Figure S22), which becomes very slow afterward. The effect of the irradiation power was also studied for the most efficient LED, i.e., $625 \mathrm{~nm}$ (Figure S22), and when the power is increased, the saturation value is slightly higher and is reached relatively faster, which can be ascribed to a better light penetration at the surface of the sample.

Further optical-reflectivity studies with LED lights were carried out at $10 \mathrm{~K}$ by cycling photoexcitation at $625 \mathrm{~nm}(30$ min; power $=16 \mathrm{~mW} \mathrm{~cm} \mathrm{~cm}^{-2}$ ) and a second irradiation with other LEDs to explore the possibility of photoreversibility of $\mathbf{1}$. The most significant changes in the spectra were observed with the 940-780 nm LEDs, as expected for the HS-to-LS photoconversion (Figure S23) for the iron(II) system. Accordingly, further deexcitation studies were carried out with $850 \mathrm{~nm}$ LED irradiation at $10 \mathrm{~K}$. During $850 \mathrm{~nm}$ LED irradiation, a drop of the absolute-reflectivity data was observed (Figure S24, left). Interestingly, the resulting spectrum significantly differs from the spectrum obtained after $625 \mathrm{~nm}$ LED irradiation at $10 \mathrm{~K}$. It is worth noting that the spectrum obtained after $850 \mathrm{~nm}$ LED irradiation is almost similar to the spectrum at $10 \mathrm{~K}$ in the dark (Figure S24, right), indicating the possibility of photodeexcitation of the metastable HS state to the LS state for 1. After irradiation, an increase of the temperature produced an augment of the reflectivity due to relaxation of the photodeexcitation state. Such an upturn was observed until $80 \mathrm{~K}$. As expected, the data obtained after this temperature exhibit behavior similar to that in the dark. The HS and LS states can thus be reversibly and efficiently ON/OFF switched by using 625 and $850 \mathrm{~nm}$ irradiation over several cycles (Figure 3, right) at $10 \mathrm{~K}$. (Photo)magnetic measurements at $10 \mathrm{~K}$ under different diode lasers also confirm the above findings (Figure S25).

To find a correlation between the interesting SCO and luminescence properties in 1, variable-temperature fluorescence measurements were carried out from 270 to $70 \mathrm{~K}$. The ligand $\mathbf{L}$ shows an emission band centered at around $565 \mathrm{~nm}$ upon excitation with $365 \mathrm{~nm}$ at room temperature (Figure S26). 1 exhibit a very interesting luminescence property, showing two broad bands centered at 524 and $570 \mathrm{~nm}$ upon excitation at $395 \mathrm{~nm}$ (Figure S27), which indicates that the luminescence property for $\mathbf{1}$ is different from that of the ligand albeit with a decreased intensity. As seen in Figure 4 (left), upon a decrease in the temperature, the luminescence intensity 
of the maximum emission at $524 \mathrm{~nm}\left(I_{524}\right)$ initially decreased and then reached the lowest value at around $150 \mathrm{~K}$. Upon a further decrease in the temperature, the emission intensity $I_{524}$ started to gradually increase up to $70 \mathrm{~K}$. Minimization of $I_{524}$ at around the SCO temperature $\left(T_{1 / 2}\right)$ of $150 \mathrm{~K}$ suggested modulation of the luminescence properties with a thermal population of the HS and LS states. The results conclude a remarkable synergistic correlation between the SCO and luminescence properties in $\mathbf{1}$.

A detailed theoretical CASSCF/NEVPT2 calculation ${ }^{34}$ revealed the ligand-field strength $\left(10 \mathrm{Dq}^{\mathrm{LS}} / 10 \mathrm{Dq}^{\mathrm{HS}} \approx 1.81\right)$ and excitation energies for light-induced excited spin-state trapping (LIESST; ${ }^{1} \Gamma \rightarrow{ }^{1} \Gamma^{*} ; \Delta \varepsilon^{\mathrm{LS}} \approx 18217 \mathrm{~cm}^{-1}$ ) and reverse LIESST $\left({ }^{5} \Gamma \rightarrow{ }^{5} \Gamma^{*} ; \Delta \varepsilon^{\mathrm{HS}} \approx 11089 \mathrm{~cm}^{-1}\right.$; Figure 4), and the role of ligands on the LIESST and reverse LIESST effects in $\mathbf{1}$ was studied also by time-dependent density functional theory (Figures S29 and S30), confirming the experimental results.

In conclusion, we have successfully prepared a $2 \mathrm{D}[4 \times 4]$ square-grid iron(II) CP by integrating $\mathrm{Fe}(\mathrm{NCSe})_{2}$ with a redox- and luminescence-active ligand. The $\mathrm{CP}$ displayed reversible thermo- and photoinduced ON/OFF spin-state switching. Intriguingly, the temperature dependence of the luminescence measurements confirmed a synergic correlation between the SCO and luminescence properties in 1 . We believe that this work will deliver an important strategy for the design and development of SCO- and luminescence-based magnetooptical materials and open up new ways for the enhancement of smart switchable materials.

\section{AUTHOR INFORMATION}

\section{Corresponding Author}

Abhishake Mondal - Solid State and Structural Chemistry Unit, Indian Institute of Science (IISc), Bangalore 560012, India; 이 orcid.org/0000-0002-5061-2326; Email: mondal@ iisc.ac.in

\section{Authors}

Subrata Ghosh - Solid State and Structural Chemistry Unit, Indian Institute of Science (IISc), Bangalore 560012, India; (ㄱ) orcid.org/0000-0003-4539-4413

Sujit Kamilya - Solid State and Structural Chemistry Unit, Indian Institute of Science (IISc), Bangalore 560012, India; (1) orcid.org/0000-0003-4881-0638

Titas Pramanik - Solid State and Structural Chemistry Unit, Indian Institute of Science (IISc), Bangalore 560012, India
Mathieu Rouzières - Centre de Recherche Paul Pascal, University of Bordeaux, UMR 5031, CNRS, Pessac 33600, France; orcid.org/0000-0003-3457-3133

Radovan Herchel - Department of Inorganic Chemistry, Faculty of Science, Palacký University, Olomouc CZ-771 46, Czech Republic; ○ orcid.org/0000-0001-8262-4666

Sakshi Mehta - Solid State and Structural Chemistry Unit, Indian Institute of Science (IISc), Bangalore 560012, India; (1) orcid.org/0000-0002-1232-4489

\section{ACKNOWLEDGMENTS}

This research work is supported by the IISc, Bangalore, India, and the Science and Engineering Research Board (Project SRG/2019/000317). R.H. acknowledges financial support from institutional sources of the Department of Inorganic Chemistry, Palacký University Olomouc, Czech Republic. S.K. thanks the Council of Scientific \& Industrial Research (CSIR), Government of India, and S.G. and S.M. thank the IISc for fellowships.

\section{REFERENCES}

(1) Coronado, E. Molecular magnetism: from chemical design to spin control in molecules, materials and devices. Nat. Rev. Mater. 2020, 5, 87-104.

(2) Zhang, C.; Yao, H.; Nie, Y.-H.; Liang, J.-Q.; Niu, P.-B. Magnetic field manipulation of spin current in a single-molecule magnet tunnel junction with two-electron Coulomb interaction. AIP $A d v$. 2018, 8, 045309-045317.

(3) Sato, O. Dynamic molecular crystals with switchable physical properties. Nat. Chem. 2016, 8, 644-656.

(4) Meng, Y.-S.; Liu, T. Manipulating Spin Transition To Achieve Switchable Multifunctions. Acc. Chem. Res. 2019, 52, 1369-1379.

(5) Senthil Kumar, K.; Ruben, M. Emerging trends in spin crossover (SCO) based functional materials and devices. Coord. Chem. Rev. 2017, 346, 176-205.

(6) Kahn, O.; Martinez, C. J. Spin-Transition Polymers: From Molecular Materials Toward Memory Devices. Science 1998, 279, 4448.

(7) Halcrow, M. A. Spin-crossover materials properties and applications; John Wiley and Sons, Inc.: Chichester, U.K., 2013.

(8) Minguez Espallargas, G.; Coronado, E. Magnetic functionalities in MOFs: from the framework to the pore. Chem. Soc. Rev. 2018, 47, 533-557.

(9) Cui, Y.; Li, B.; He, H.; Zhou, W.; Chen, B.; Qian, G. MetalOrganic Frameworks as Platforms for Functional Materials. Acc. Chem. Res. 2016, 49, 483-493.

(10) Kitagawa, S.; Kitaura, R.; Noro, S.-i. Functional Porous Coordination Polymers. Angew. Chem., Int. Ed. 2004, 43, 2334-2375.

(11) Halder, G. J.; Kepert, C. J.; Moubaraki, B.; Murray, K. S.; Cashion, J. D. Guest-Dependent Spin Crossover in a Nanoporous Molecular Framework Material. Science 2002, 298, 1762-1765.

(12) Qiu, Y.-R.; Cui, L.; Cai, P.-Y.; Yu, F.; Kurmoo, M.; Leong, C. F.; D’Alessandro, D. M.; Zuo, J.-L. Enhanced dielectricity coupled to spin-crossover in a one-dimensional polymer iron(ii) incorporating tetrathiafulvalene. Chem. Sci. 2020, 11, 6229-6235.

(13) Rice, A. M.; Martin, C. R.; Galitskiy, V. A.; Berseneva, A. A.; Leith, G. A.; Shustova, N. B. Photophysics Modulation in Photoswitchable Metal-Organic Frameworks. Chem. Rev. 2020, 120, 8790.

(14) Garg, S.; Schwartz, H.; Kozlowska, M.; Kanj, A. B.; Müller, K.; Wenzel, W.; Ruschewitz, U.; Heinke, L. Conductance Photoswitching 
of Metal-Organic Frameworks with Embedded Spiropyran. Angew. Chem., Int. Ed. 2019, 58, 1193-1197.

(15) Feng, J.; Xu, Z.; Dong, P.; Yu, W.; Liu, F.; Jiang, Q.; Wang, F.; Liu, X. Stimuli-responsive multifunctional metal-organic framework nanoparticles for enhanced chemo-photothermal therapy. J. Mater. Chem. B 2019, 7, 994-1004.

(16) Yao, Z.-Q.; Xu, J.; Zou, B.; Hu, Z.; Wang, K.; Yuan, Y.-J.; Chen, Y.-P.; Feng, R.; Xiong, J.-B.; Hao, J.; Bu, X.-H. A Dual-StimuliResponsive Coordination Network Featuring Reversible Wide-Range Luminescence-Tuning Behavior. Angew. Chem., Int. Ed. 2019, 58, 5614-5618.

(17) Li, Z.-Y.; Dai, J.-W.; Damjanović, M.; Shiga, T.; Wang, J.-H.; Zhao, J.; Oshio, H.; Yamashita, M.; Bu, X.-H. Structure Switching and Modulation of the Magnetic Properties in Diarylethene-Bridged Metallosupramolecular Compounds by Controlled CoordinationDriven Self-Assembly. Angew. Chem., Int. Ed. 2019, 58, 4339-4344.

(18) Jiao, Y.; Zhu, J.; Guo, Y.; He, W.; Guo, Z. Synergetic effect between spin crossover and luminescence in the $\left[\mathrm{Fe}(\mathrm{bpp})_{2}\right]\left[\mathrm{BF}_{4}\right]_{2}$ (bpp $=2,6$-bis $($ pyrazol-1-yl $)$ pyridine $)$ complex. J. Mater. Chem. C 2017, 5, 5214-5222.

(19) Estrader, M.; Salinas Uber, J.; Barrios, L. A.; Garcia, J.; LloydWilliams, P.; Roubeau, O.; Teat, S. J.; Aromi, G. A Magneto-optical Molecular Device: Interplay of Spin Crossover, Luminescence, Photomagnetism, and Photochromism. Angew. Chem., Int. Ed. 2017, $56,15622-15627$.

(20) Benaicha, B.; Van Do, K.; Yangui, A.; Pittala, N.; Lusson, A.; Sy, M.; Bouchez, G.; Fourati, H.; Gomez-Garcia, C. J.; Triki, S.; Boukheddaden, K. Interplay between spin-crossover and luminescence in a multifunctional single crystal iron(ii) complex: towards a new generation of molecular sensors. Chem. Sci. 2019, 10, 67916798.

(21) Yuan, J.; Wu, S. Q.; Liu, M. J.; Sato, O.; Kou, H. Z. Rhodamine 6G-Labeled Pyridyl Aroylhydrazone Fe(II) Complex Exhibiting Synergetic Spin Crossover and Fluorescence. J. Am. Chem. Soc. 2018, 140, 9426-9433.

(22) Wang, J. L.; Liu, Q.; Meng, Y. S.; Liu, X.; Zheng, H.; Shi, Q.; Duan, C. Y.; Liu, T. Fluorescence modulation via photoinduced spin crossover switched energy transfer from fluorophores to $\mathrm{Fe}(\mathrm{II})$ ions. Chem. Sci. 2018, 9, 2892-2897.

(23) Lochenie, C.; Schötz, K.; Panzer, F.; Kurz, H.; Maier, B.; Puchtler, F.; Agarwal, S.; Köhler, A.; Weber, B. Spin-Crossover Iron(II) Coordination Polymer with Fluorescent Properties: Correlation between Emission Properties and Spin State. J. Am. Chem. Soc. 2018, 140, 700-709.

(24) Meneses-Sánchez, M.; Piñeiro-López, L.; Delgado, T.; BartualMurgui, C.; Muñoz, M. C.; Chakraborty, P.; Real, J. A. Extrinsic vs. intrinsic luminescence and their interplay with spin crossover in $3 \mathrm{D}$ Hofmann-type coordination polymers. J. Mater. Chem. C 2020, 8, $1623-1633$.

(25) Delgado, T.; Meneses-Sánchez, M.; Piñeiro-López, L.; BartualMurgui, C.; Muñoz, M. C.; Real, J. A. Thermo- and photo-modulation of exciplex fluorescence in a 3D spin crossover Hofmann-type coordination polymer. Chem. Sci. 2018, 9, 8446-8452.

(26) Casanova, D.; Llunell, M.; Alemany, P.; Alvarez, S. The Rich Stereochemistry of Eight-Vertex Polyhedra: A Continuous Shape Measures Study. Chem. - Eur. J. 2005, 11, 1479-1494.

(27) Sciortino, N. F.; Neville, S. M. Two-Dimensional Coordination Polymers with Spin Crossover Functionality. Aust. J. Chem. 2014, 67, $1553-1562$.

(28) Mondal, A.; Li, Y.; Chamoreau, L.-M.; Seuleiman, M.; Rechignat, L.; Bousseksou, A.; Boillot, M.-L.; Lescouëzec, R. Photoand thermo-induced spin crossover in a cyanide-bridged $\left\{\mathrm{Mo}_{2}{ }_{2} \mathrm{Fe}^{\mathrm{II}}{ }_{2}\right\}$ rhombus molecule. Chem. Commun. 2014, 50, 2893-2895.

(29) Mondal, A.; Li, Y.; Herson, P.; Seuleiman, M.; Boillot, M.-L.; Rivière, E.; Julve, M.; Rechignat, L.; Bousseksou, A.; Lescouëzec, R. Photomagnetic effect in a cyanide-bridged mixed-valence $\left\{\mathrm{Fe}_{2}{ }_{2} \mathrm{Fe}_{2}{ }_{2}\right\}$ molecular square. Chem. Commun. 2012, 48, 5653-5655.

(30) Slichter, C. P.; Drickamer, H. G. Pressure-Induced Electronic Changes in Compounds of Iron. J. Chem. Phys. 1972, 56, 2142-2160.
(31) Aguilà, D.; Prado, Y.; Koumousi, E. S.; Mathonière, C.; Clérac, R. Switchable $\mathrm{Fe} / \mathrm{Co}$ Prussian blue networks and molecular analogues. Chem. Soc. Rev. 2016, 45, 203-224.

(32) Ababei, R.; Pichon, C.; Roubeau, O.; Li, Y.-G.; Bréfuel, N.; Buisson, L.; Guionneau, P.; Mathonière, C.; Clérac, R. Rational Design of a Photomagnetic Chain: Bridging Single-Molecule Magnets with a Spin-Crossover Complex. J. Am. Chem. Soc. 2013, 135, 1484014853.

(33) Kamilya, S.; Ghosh, S.; Li, Y.; Dechambenoit, P.; Rouzières, M.; Lescouëzec, R.; Mehta, S.; Mondal, A. Two-Step Thermoinduced Metal-to-Metal Electron Transfer and ON/OFF Photoswitching in a Molecular $\left[\mathrm{Fe}_{2} \mathrm{Co}_{2}\right]$ Square Complex. Inorg. Chem. 2020 DOI: 10.1021 /acs.inorgchem.0c02053.

(34) Neese, F. Software update: the ORCA program system, version 4.0. Wiley Interdiscip. Rev.: Comput. Mol. Sci. 2018, 8, e1327. 